ESCRIBIR ANIMALES

\title{
SOBRE LAS PEQUEÑAS PROSAS ZOOLÓGICAS DE JUAN JOSÉ ARREOLA Y JOÃO GUIMARÃES ROSA
}

\begin{abstract}
Julieta Yelin es Dra. en Humanidades con mención en Literatura por la Universidad Nacional de Rosario. Su Tesis se titula: "Historias de animales: La fábula y el bestiario en la Literatura Latinoamericana de la segunda posguerra”. Actualmente es becaria posdoctoral de CONICET y desarrolla una investigación sobre la primera recepción de la obra de Franz Kafka en el ámbito hispanoamericano.

E-mail: julietayelin@yahoo.com.ar
\end{abstract}

\section{Resumo:}

O presente artigo propõe uma leitura de Bestiario de Juan José Arreola e dos “Zoo" de João Guimarães Rosa à luz do agravamento da crise dos imaginários de animais / do animal no período posterior à Segunda Guerra Mundial.

\begin{abstract}
Résumé:
Le présent travail se propose de réaliser une lecture de Bestiario de Juan José Arreola et les «Zoo » de João Guimarães Rosa à la lumière de l'aggravement de la crise des imaginaires d'animaux / de l'animal dans le période de la deuxième post-guerre.
\end{abstract}

En su ensayo “¿Por qué miramos a los animales?”, John Berger (2001) reflexiona sobre el lugar de los animales en el imaginario del hombre contemporáneo. Y la idea de lugar no es metafórica; la pregunta es, concretamente, ¿dónde están los animales en nuestros tiempos? ¿Por qué ya no podemos verlos? La respuesta aventura que los animales, tal como el hombre los ha conocido y representado a lo largo de milenios, han desaparecido, se han borrado de su horizonte. El vertiginoso crecimiento de las grandes urbes, el desarrollo de las industrias textil y alimenticia y la progresiva desaparición del campesinado son algunas de las causas de este distanciamiento que, más allá de toda nostalgia romántica, ha tenido efectos concretos sobre el devenir de la relación hombreanimal.

Esa desaparición es constatable, según Berger, en la emergencia moderna de nuevos significantes del animal. Uno de ellos, y quizás el más significativo, es el zoológico, espectáculo público y dominio geográfico y natural indudablemente cargado, como señala Randy Malamud (1998), de evocaciones imperialistas. Así, el zoológico aparece como una empresa al tiempo que como una buena metáfora de un estadio del capitalismo en el que se ordenan y explotan los frutos de la repartición imperial. Ese sentido de apropiación es retomado por Berger para explicar la decadencia del imaginario animal en la contemporaneidad: convertido en un bien, en una cosa -ya sea para la explotación científica, industrial o meramente zoológica- el animal en tanto tal, es decir, en tanto "otro" desconocido, ha sido borrado, negado, aniquilado. Es en este sentido que en un artículo dedicado enteramente al zoológico público, lo define como un monumento a la ausencia, a la imposibilidad moderna de 'ver' a los animales, al fracaso final del encuentro. Así, señala 
la paradoja fundacional de una institución que ubica el animal en un lugar aparentemente central - en tanto protagonista del espectáculo -, al tiempo que, mediante la violencia efectiva y simbólica a la que lo somete, lo convierte en algo completamente marginal, desplazado, fuera de sí.

Mires como mires a esos animales, aún si el animal está contra los barrotes, a menos de un metro de distancia, mirando hacia afuera en dirección del público, estás viendo algo que se ha vuelto absolutamente marginal, y toda la concentración de la que puedas ser capaz no será nunca suficiente para volverlo central.”

(Berger, 1978, p. 822)

Como un tipo más de museo, además de una clara afirmación del poder colonial moderno, los zoológicos públicos, desde su nacimiento a inicios del siglo XIX, se propusieron restituir aquella imagen del animal perdida a través de la rigurosa creación de catálogos vivientes que pudieran dar cuenta de la inmensa variedad del mundo natural. Estas reconstrucciones, destinadas fundamentalmente a la instrucción de los niños, se proponían mantener presente - visible - esa vida paralela a la del hombre, al tiempo que firmaban su definitiva acta de defunción. Desligado de su medio natural, es decir, sometido a condiciones climáticas, lumínicas y alimenticias artificiales, el animal es separado de su conducta 'natural' y, en respuesta a esa separación, asume una conducta privativamente humana: la indiferencia. La gente va al zoo a mirar a los animales pero en ningún momento puede encontrarse con su mirada, pues el aislamiento a que están sometidos los inmuniza contra todo contacto. "Este intercambio de miradas entre el hombre y el animal, que ha jugado un rol crucial en el desarrollo de las sociedades humanas y con el cual los hombres han convivido hasta hace menos de un siglo, se ha extinguido.” (Berger, 1978, p. 823-4)

El completo aislamiento, materializado por la jaula - o por cristales en muchos zoológicos modernos -, es el signo más concreto de la necesidad de restituir una separación perdida, una distancia que hacía posible la distinción y, con ella, la percepción. Los animales están allí física y materialmente, pero sustraen su identidad animal, su ánima, precisamente aquello que la tradición filosófica dominante en Occidente les negó.

Tan frecuentes como los sonidos de los animales en el zoo son los gritos de los niños que preguntan: ¿Dónde está? ¿Por qué no se mueve? ¿Está muerto? Se podría resumir así el sentimiento de gran parte de los visitantes: ¿por qué estos animales son menos de lo que pensaba? [...] ¿Qué esperas? Esto que has venido a ver no es una cosa muerta, es un ser viviente. Dirige su propia vida. ¿Por qué eso debería coincidir con el hecho de ser claramente visible? (Berger, 1978, p. 822)

Con todo, su presencia ausente no es el peor de los males; lo más desolador para el visitante del zoo, lo realmente frustrante es la falta de reciprocidad. Las bestias no tienen ningún interés en nosotros. Por otra parte, ¿por qué habrían de tenerlo? Somos nosotros los

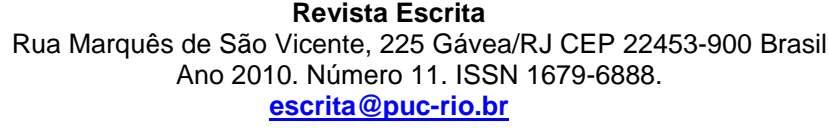


que los exponemos y observamos; se trata de una relación de poder unilateral en la que, como señala Malamud (1998), se pueden reconocer algunos elementos del voyeurismo. Tomando la definición de J. Rudinow (1979) Malamud que sostiene, como el espectador del zoo, que "El voyeur busca un espectáculo, la revelación del objeto de su interés, que algo o alguien se abra para su inspección y contemplación; pero ninguna apertura ni revelación recíproca es concedida” (Malamud, 1998, p. 250). ${ }^{\text {ii }}$

La literatura también pensó ese problema, y no es casual que lo haya hecho con mayor asiduidad en los años cincuenta, precisamente cuando, tras el fin de la Segunda Guerra Mundial, los discursos humanistas atravesaban su crisis más profunda. Los escritores de la posguerra van frecuentemente al zoo, al jardín botánico, al acuario, como si buscaran un modo - el único, tal vez, después de los brutales efectos del nazismo - de hablar del mundo humano. Cortázar visita el acuario del Jardin des Plantes (“Axolotl”); Silvina Ocampo imagina un cambio de posiciones ("Fuera de las jaulas”); Lispector envía a las mujeres de sus relatos a purgar su malestar existencial en la impersonalidad de la naturaleza del Jardín Botánico, o a buscar el odio en el zoo (“Amor” y “O búfalo”). De pronto, hay jaulas y bestias por todas partes. Pero ¿qué ven los escritores en el zoo? ¿Cuáles son los efectos literarios de sus observaciones?

Nos detendremos aquí en dos escrituras del zoo que tal vez nos permitan esbozar algunas respuestas. Se trata de los “Zoo” de João Guimarães Rosa y el Bestiario de Juan José Arreola, compendios de pequeñas prosas que, creemos, dan cuenta de esa compleja relación que establece el visitante frente a las imágenes de las bestias enjauladas, apenas recuerdos de una vida animal perdida.

El Bestiario de Juan José Arreola es el producto, como tantos bestiarios, de la combinación de dos ejercicios al menos aparentemente contrapuestos: la observación meticulosa y la imaginación lírica; es decir: de sus visitas al zoológico en compañía de Héctor Xavier - autor de las ilustraciones que acompañan la lujosa edición realizada por la Universidad Nacional Autónoma de México, titulada Punta de plata - iii y de su fascinación por el Bestiario espiritual de Paul Claudel. Allí, Arreola describe en dieciocho pequeñas prosas poéticas cada uno de los animales presentados como un rico catálogo de vida fuera de uso, reliquias de un pasado lejano conservadas dentro de las jaulas, solas y extemporáneas. Así, ante el hipopótamo, ese "Buey neumático" “jubilado por la naturaleza”, se pregunta: “¿Qué hacer con el hipopótamo, si ya sólo sirve como draga y aplanadora de los terrenos palustres, o como pisapapeles de la historia?” (Arreola, 1997, p. 98). Aquí, y en el resto de las metáforas, los animales son comparados con objetos, con fragmentos o engranajes de máquinas en desuso. Escribe del rinoceronte: "Ya en cautiverio, el rinoceronte es una bestia melancólica y oxidada. Su cuerpo de muchas piezas ha sido 
armado en los derrumbaderos de la prehistoria, con láminas de cuero troqueladas bajo la presión de los niveles geológicos.” (Arreola, 1997, p. 80) Y del elefante: "Viene desde el fondo de las edades y es el último modelo terrestre de maquinaria pesada, envuelto en su funda de lona”(Arreola, 1997, p. 91).

La escena del encuentro con el animal en estos textos de Arreola está signada por el fracaso. Al concebir el zoo como un museo, el Bestiario es un testimonio de la imposibilidad de ver en los animales más que un recuerdo, una vaga imagen de lo que alguna vez fueron y significaron. La metáfora animal, que alguna vez tuvo la capacidad de hablar de lo humano de modo tan eficaz, se orienta hacia el terreno de lo inanimado, y más aún, de lo caduco. La alusión a lo maquínico desarticulado y anacrónico puede pensarse en relación a un discurso crítico acerca de la modernidad, que atraviesa de modo más o menos manifiesto muchos de los textos de Arreola. Si bien no es posible hablar de una posición romántica respecto del mundo natural, si existe en Arreola una pulsión de retorno a un estado primitivo imaginario en el cual el hombre era más hombre, la mujer más mujer, el animal más animal, y así, las relaciones entre ellos más auténticas.

Esa visión pesimista de la modernidad es subsidiaria del moralismo y la misoginia ${ }^{\text {iv }}$ que se le han atribuido con frecuencia y que, en efecto, aparecen en muchos de sus relatos, especialmente en aquellos que registran de modo más visible la impronta kafkiana, como "El guardagujas”, "El rinoceronte”, “En verdad os digo” o "La mujer amaestrada”, tal vez la más perturbadora y genial de sus narraciones. En el caso del Bestiario, la fuerte impronta moral está ligada también a su vínculo con dos tradiciones que durante siglos han utilizado el imaginario teriomorfo como un espejo en el que se reflejan las virtudes y los defectos del hombre. Una es, evidentemente, la del bestiario medieval, y la otra, la de la fábula clásica.

Mi manera de tratar a los animales, aunque tiene rasgos propios, está condicionada por la tradición que principia aparentemente con Esopo, pasa por toda una serie de autores sin importancia, llega a La Fontaine y a los fabulistas modernos. [...] De las fábulas de Esopo y La Fontaine a los tratamientos que hoy se hacen de los animales existe una gran distancia, pero en el fondo las fábulas clásicas y los apólogos modernos están cortados con el mismo patrón: unas y otros se preocupan por aclarar el paso del hombre sobre la tierra. (Carballo, 1965, p. 399-400)

La búsqueda de la inscripción de lo humano en el imaginario animal se vislumbra desde la primera línea del prólogo del Bestiario, que preanuncia una hermenéutica antropomórfica, siempre descendente, degradante: “Ama al prójimo porcino y gallináceo, que trota gozoso a los crasos paraísos de la posesión animal” (Arreola, 1997, p. 79).

Sin embargo, esta impronta humanista encuentra en sus retratos de animales una resistencia que, con el tiempo, se convertirá en lo más interesante de la escritura de Arreola. La denuncia de una cosificación de las bestias presente en el Bestiario se patentizará, en sus textos posteriores, en una ruptura con la tradición de la metáfora animal - si los animales se han convertido en figuras fantasmagóricas, ¿cómo establecer una relación de equivalencia? 
-. En dichas narraciones, la metáfora animal deviene un proceso que habilita la percepción de una zona común, de un espacio que podríamos denominar transicional: de un lugar ni hombre ni animal que, sin embargo, es - en un momento imposible de medir, relatar o fotografiar - habitado por ambos, que se sitúa exactamente entre ambos. Tal vez la noción que más se aproxime a esa transformación es la de devenir-animal propuesta por Deleuze y Guattari, en la que la oposición humano-animal es puesta en cuestión mediante una ligazón íntima entre ambas partes.

Los cuentos 'kafkianos' de Arreola, a los que hemos hecho referencia, están plagados de imaginarios ambiguos, contradictorios - que ya pueden leerse en el enunciado “crasos paraísos”-, transicionales: hombre-animal, mujer-animal, hombre-mujer que operan contra toda moral esencialista o jerárquica.

\section{III}

Veamos ahora qué sucede en otra escritura del zoo: la de João Guimarães Rosa. Los “Zoo” de Rosa son también un conjunto de pequeñas prosas poéticas. Las mismas fueron incluidas póstumamente en el libro misceláneo Ave, palabra, planificado por el propio Rosa poco tiempo antes de morir y concluido por uno de sus más asiduos estudiosos brasileros, Pablo Rónai, quien sumó algunos textos a los ya ordenados por el autor. El libro es una recopilación de notas de viaje, fragmentos de diario, poemas, cuentos, reflexiones, que forman el conjunto de sus colaboraciones, discontinuas y esporádicas, en revistas y diarios brasileros en el período 1947-1967.

Los “Zoo" de Ave, palabra son seis: el de Hagenbeck-Tierpark de HamburgoStellingen, dividido en dos partes; ${ }^{\mathrm{v}}$ el del Parc Zoologique del Bois de Vincennes; ${ }^{\text {vi }}$ el del Jardin des Plantes de París; ${ }^{\text {vii }}$ el de Whipsnade Park, de Londres ${ }^{\text {viii }}$ y el de Quinta da Boa Vista, de Río de Janeiro, ${ }^{\mathrm{ix}}$ y constituyen, junto con los dos acuarios -uno de Nápoles ${ }^{\mathrm{x}}$ y otro de Berlín ${ }^{\mathrm{xi}}$-, y pese a estar dispersos a lo largo del libro, una unidad que podría permitirles conformar un librito aislado. El mismo Rosa lo había pensado: "Tenho idéia de escrever um bestiário amoroso, aproveitando todas as minhas notas e impressões de jardins zoológicos” (Martins Costa, 2002, p.68).

Los zoos y acuarios de Rosa pueden leerse como un nuevo intento de pensar los animales y lo animal, tan presentes en toda su obra, o mejor, de pensar el problema de la representación de los animales, de la relación entre hombres y animales. Sólo que esta vez esa relación ha mudado en no-relación y nada del orden de lo natural se hace presente en el encuentro: "Eu e o peixe no aquário temos nenhuma naturalidade.” (Rosa, 2001, p. 61)

Como en el caso de Arreola, se trata de pequeñas y rápidas estampas aisladas que, acumuladas, conforman la narrativa del paseo por el zoológico: de jaula en jaula, de pecera en pecera, captando una escena tras otra, el observador intenta construir una totalidad que una y otra vez se le escapa. Es el fracaso al que alude Berger, y que se vincula, como él 
señala, a la poca animalidad de las bestias enjauladas. Y quizás también, podríamos agregar, a que la ausencia del animal pone en cuestión la identidad humana. El paseante va en busca de algo que ya no existe: el animal "otro”, su opuesto y la garantía de su identidad no-animal.

En los textos de Rosa el paseo se consuma en la redacción de un inventario, gesto que recuerda las anotaciones de sus libretas de viajes al sertão minero, donde apuntaba con la minuciosa atención del extranjero los detalles de la vida, las costumbres, la lengua, la flora y la fauna, desde la multiplicidad cromática de los bueyes ${ }^{\text {xii }}$ hasta los detalles de la pérdida de un cuerno vacuno. ${ }^{\text {xiii }}$ Sin embargo, a diferencia de aquel trabajo de campo reelaborado narrativamente en sus relatos y novelas, en las prosas denominadas "Zoo" el animal deviene una pura imagen, condensada y estilizada al máximo en la que la forma breve y el lirismo contribuyen a generar un efecto fotográfico, o más bien pictórico, que nos reenvía a la idea de museo planteada por Berger. Rosa se detiene frente a cada jaula como frente a un cuadro y da cuenta de una impresión en la que la imagen poética prima por sobre la narración. Los animales enjaulados están más cerca de la poesía, parece intuir Rosa, que del relato.

Mientras que en sus cuentos y novelas las historias de animales y vaqueros se multiplican al infinito, en las prosas zoológicas se elimina casi todo elemento narrativo, como si nada pudiese pasar allí con los animales, entre los hombres y los animales. Apenas es posible registrar un relato, fragmentario y velado, en el zoo del Jardín des Plantes. Es la pequeña fábula de la serpiente cascabel y el ratoncito blanco:

Uma cascavel, nas encolhas. Sua massa infame.

Crime: prenderam, na gaiola da cascavel, um ratinho branco. O pobrinho se comprime num dos cantos do alto da parede de tela, no lugar mais longe que pôde. Olha para fora, transido, arrepiado, não ousando choramingar. Periodicamente, treme. A cobra ainda dorme. (Rosa, 2001, p. 273)

Luego, tres jaulas más adelante: "Perdoar a uma cascavel: exercício de santidade" (Rosa, 2001, p. 274), y más tarde: "Pela cascavel, por transparência, vê-se o pecado mortal” (Rosa, 2001, p. 275). Pero el paseo continúa: cornejas, grandes serpientes reales e imaginarias - pitón reticulado, pitón de Sabá, vívora-rinoceronte -, hasta que, de pronto, se enuncia una plegaria: "Meu Deus, que pelo menos a morte do ratinho branco seja instantânea!” (Rosa, 2001, p. 277) Y más tarde, “Tenho de subornar um guarda, para que liberte o ratinho branco da jaula de cascavel. Talvez ainda não seja tarde.” (Rosa, 2001, p. 278) Finalmente, a tres instantáneas del final, la moraleja, que restituye el orden natural de las cosas: "Mas, ainda que eu salve o ratinho branco, outro terá de morrer em seu lugar. E, dêste outro, terei sido eu o culpado”. (Rosa, 2001, p. 279)

En las descripciones aisladas, en cambio, ese orden es suspendido, y los animales aparecen en toda su materialidad, como en los textos de Arreola: “A massa principal: 
elefante. Um volume fechado: rinoceronte. O amorfo arremedado: hipopótamo” (Rosa, 2001, p.95-6); "Vê-se: o rinoceronte inteiro maciço, recheado de chumbo verde” (Rosa, 2001, p.314). Aislados, incómodos, a veces humillados: “A girafa -sem intervenção na paisagem: ímpar, ali no meio, feito uma gravata” (Rosa, 2001, p.93); “As panteras: contristes, contramalhadas, contrafeitas” (Rosa, 2001, p.93)

Es curioso el modo con que los animales urbanos adquieren para Rosa, que en su escritura del sertão construyó un bestiario rural - es decir, en el que los animales continúan siendo animales -, una dimensión completamente diferente. Si bien la representación de las bestias del zoo retoma creativamente la agudeza y precisión de la observación naturalista, ésta tiende aquí a producir el efecto contrario: en lugar de apoyar la verosimilitud, acentúa el carácter irreal de los animales enjaulados. Aislados de su contexto natural, aparecen como fantasmas, como imágenes abstractas que invitan a la alusión metafórica, a la comparación, a la parodia. De allí el efecto humorístico de algunas de estas prosas, un humor diferente del provocado en ocasiones por los animales sertaneros. Éstos se encuentran muchas veces, es cierto, en situaciones que rayan lo absurdo o lo grotesco, pero esas situaciones se hallan insertas en un contexto más general de representación de la vida rural en la que los animales constituyen, por decirlo de algún modo, un 'asunto serio', al tiempo que vehiculizan una voluntad -afortunadamente nunca realizada - de alcanzar un sentido trascendente, de sostener una afirmación existencial sobre el ser humano. En los “Zoo” esa voluntad desaparece y es sustituida por una intención preponderantemente estética. En efecto, algunas de estas imágenes zoológicas recuerdan, como señala W. Benavidez (1993), las greguerías del Bestiario de Ramón Gómez de la Serna. ${ }^{\text {xiv }}$

Es interesante el modo en que los animales - uno de los principales sostenes de la construcción de la heroicidad del hombre del sertão en la narrativa de Rosa, de ese hombre en continua lucha con la naturaleza, encerrados en las jaulas, sacados del contexto épico, de la vida rústica y difícil de la región minera - devienen objeto de un trabajo lúdico del lenguaje $^{\mathrm{xv}}$ y se distancian radicalmente de lo humano. Si en la narrativa sertanera el animal es lo más próximo, lo más familiar para el hombre - también en el sentido de lo siniestro freudiano -, en los zoo se convierte en algo completamente ajeno, algo con lo que no se puede establecer más contacto que el visual, algo de lo que no hay demasiado que contar.

Para terminar, una pequeña nota sobre un texto en el que Rosa tematiza también la figura del animal como pieza de museo, y que de algún modo cierra un círculo en lo referente a las representaciones teriomorfas. Nos referimos a "O burro e o boi no presépio (Catálogo esparso)”, también de Ave, palabra; en él, Rosa describe en pequeños poemas la presencia del burro y del buey en veintiséis representaciones pictóricas de pesebres. Los poemas están numerados y son precedidos del nombre del artista, el nombre del cuadro y del museo en el cual se encuentran. Como en los “Zoo", las imágenes se suceden mostrando a los animales de modo fragmentario, señalando su materialidad: "Obscientes sorrisos / - orelhas, chifres, focinhos, / claros- / fortes como estrelas” (Rosa, 2001, p. 251), 
su color, su forma: "De perfil, gris, / adiante (para que o Menino o veja) / o Burrinho. / O Boi ainda não se destacou /da mansa treva.” (Rosa, 2001, p. 250); “Ao plano e inefável / o Burrinho se curva, / numa inocência de forma.” (Rosa, 2001, p. 256). Pero en estos animales de museo esas formas tendientes a la reificación se alternan con otras humanizantes. El burro y el buey, figuras rústicas y útiles que simbolizan la sencillez con que es celebrado el nacimiento de Cristo, están dotados de emociones que las bestias sertaneras de la narrativa de Rosa no poseían: son tiernos, humildes, nobles, están tristes, suplicantes, más aún: están desnudos, una calificación imposible de atribuir a un animal en su medio natural: "Nus como Jesus / posto entre húmus e plantas, / num canteiro.” (Rosa, 2001, 257)

Estas representaciones de animales doblemente mediadas son aún más abstractas que las producidas por los “Zoos”, pues dan cuenta de un distanciamiento mayor entre la mirada y el animal. Si los relatos del sertão se caracterizan por su impronta naturalista que hace que sea posible ver, oír, e incluso oler a los animales, cuya relación con los personajes humanos no había sido despojada de una cierta violencia -, y los “Zoo” por una predominancia poética que, enfatizando el aislamiento de las bestias, genera imágenes abstractas y líricas, aquí, en los pesebres, el doble juego de pintura y escritura da lugar a la reaparición de la dimensión simbólica de los animales - muy ligada, es evidente, al carácter religioso de los cuadros que funcionan como soporte de los poemas -, y todos los elementos formales parecen estar a su servicio. De este modo, Rosa retorna a la tradición religiosa y simbólica del animal, luego de haber transitado el camino de la crisis del imaginario, ese que va de los animales-todavía-animales del universo rural a los animalesobjeto del jardín zoológico. 


\section{REFERÊNCIAS BIBLIOGRÁFICAS:}

ARREOLA, J. J. Narrativa completa. México: Alfaguara, 1997.

BENAVIDEZ, W. Los “Zoo” y otras prosas de João Guimarães Rosa. Montevideo:

Ediciones de la Banda Oriental, 1993.

BERGER, J. «Le zoo ». En: Critique N 375-376 «L'animalité » (agosto-septiembre). Paris: Éditions du Minuit, 1978. 2001.

“¿Por qué miramos a los animales?”. En: Mirar, Barcelona, Ed. Gustavo Gili,

CARBALLO, E. “Juan José Arreola”. En: Diecinueve protagonistas de la literatura mexicana del siglo XX. México: Empresas editoriales S.A, 1965.

CORTÁZAR, J. “Axolotl”. En: Cuentos completos I. Bs. As.: Alfaguara, 1994.

DELEUZE, G. y GUATTARI, F. Kafka. Por una literatura menor. México: Era, 1983. "1730. Devenir-intenso, devenir-animal, devenir-imperceptible...”. En: Mil mesetas. Capitalismo y esquizofrenia. Valencia: Pre-textos, 1988.

LISPECTOR, C. “Amor” y “O búfalo”. Em: Laços de família. Lisboa: Relógio D’Água, 1990.

MALAMUD, R. Reading Zoos. Representations of Animals and Captivity. New York: University Press, 1998.

MARTINS COSTA, A. L. João Guimarães Rosa, Viator. Tesis Doctoral presentada en la Universidade Estadual do Rio de Janeiro (inédita), 2002.

OCAMPO, S. "Fuera de las jaulas”. En: Cuentos completos I. Bs. As.: Emecé, 1999.

ROSA, J. G. Cuaderno de notas del viaje de 1952 (E-28), Arquivo Museu de Literatura Brasileira de la Fundação Casa de Rui Barbosa (fotocopias), 1952. . Ave, palabra. Rio de Janeiro: Nova Fronteira Editora, 2001.

RUDINOW, J. "Representation, Voyeurism, and the Vacant Point of View". En Philosophy and Literature 3.2 (fall), 1979.

\footnotetext{
${ }^{\text {i }}$ Citamos en todos los casos nuestra traducción, realizada a partir de la versión francesa aparecida en la revista Critique 375-376 (Berger, 1978).

${ }^{i i}$ La traducción es nuestra.

iii El Bestiario fue publicado nuevamente en 1962 como parte del Confabulario total, sin ilustraciones, con un nuevo prólogo -el anterior hacía referencia a los dibujos de Xavier -, y con el agregado de cinco prosas.

iv Véase, por ejemplo, un texto como "La boa”. En su entrevista con Emmanuel Carballo (1965), Arreola declara que el texto es en realidad una evocación del rol femenino en el acto sexual, entendido como un "acto de devorar". También afirma que en su descripción de la ingesta del conejo "la absorción es el coito y la digestión el embarazo" (p. 398-99). En oposición a la buena, seductora voraz -y clarísimo referente fálico-, el hombre es representado como un tierno e inofensivo conejito.

v Diario O Globo, 11 de marzo de 1961 y Revista Pulso, 29 de abril de 1967. Las fechas de la primera publicación de cada uno de los textos ha sido tomada de la primera edición de Ave, Palabra (Rosa 1970).

${ }^{v i}$ Diario O Globo, 29 de abril de 1961.

vii Diario O Globo, 24 de junio de 1961.
} 
viii Revista Pulso, 7 de enero de 1967.

${ }^{\text {ix }}$ Revista Pulso, $1^{\circ}$ de abril de 1967.

${ }^{x}$ Revista Letras e Artes (suplemento de A Manhã), 11 de mayo de 1954, y Correio da Manhã, 21 de diciembre de 1957.

xi Revista Pulso, 18 de febrero de 1967.

xii “Cores de bois: baetão; fumaço claro; fumaço escuro; baetão; Jaguanês; branco; baio; pigarço (ou cirigado): amarelo, com barriga clara; careta; vermelho ou preto de cara branca; azulego. [...] Borralho amarelo (pintinhas finas). Pintado roseo. Jovanês castanho. Borralho preto (pintinhas pequenas). Borralho roseo. Baetão (pintado de preto no cinzento).” (Rosa 1952: 10 y 13).

xiii "Vaca com um chifre descascado. Põe-se pixe. A ponta sangra, mole. Volta a endurecer, mas não nasce outro chifre. (Para perder o chifre, às vezes basta uma pancadinha: o chifre pula longe. Às vezes por bater no chão. O que há agora é escuro, duro, como um osso. Depois que endurece: mas fica assimétrico. Aqui (talvez pela pastagem): a fixidez das épocas de parição.” (Rosa 1952: 11).

xiv Según Javier Marías la greguería "significa un cambio de perspectiva al mirar las cosas, una inclusión de ellas en un nuevo contexto, un obligarlas a asumir una función que de por sí no tienen, y ese choque con lo otro hace que brote una especial iluminación sobre ellas; esto es propio de toda metáfora; pero la greguería añade a su propósito lírico una envoltura humorística o irónica" (Benavidez, 1993, p. 23). De allí lo apropiado del procedimiento de la greguería para las bestias enjauladas. Veamos algunas greguerías del Bestiario de Gómez de la Serna: "Las serpientes son las corbatas de los árboles"; "El búfalo es el toro jubilado de la prehistoria"; "Las golondrinas son los pájaros vestidos de etiqueta” (Gómez de la Serna, 2007). Y algunas de Rosa: "Um leão ruge a plenos trovões” (Rosa, 2001, p. 92); “As focas beijam-se inundadamente” (p. 93); “A zebra se coça contra uma árvore, tão de leve, que nem uma listra se apaga” (p. 94); "A pantera negra; e as estrêlas?” (p. 96)

${ }^{x v}$ Por ejemplo, en la creación de neologismos: “O porco espinho: espalitou-se!” (p. 92). 